\title{
The Idea of Vulnerability in Healthcare Law and Ethics: From the
}

\author{
Margins to the Mainstream?
}

\author{
Mary Neal ${ }^{1}$
}

\section{Introduction}

Without vulnerability, there would be no need for healthcare, or law, or ethics. Each of these systems owes its existence to the fact that human beings are open, fragile, and fallible. The idea of vulnerability might seem to deserve a prominent place in thinking and writing about healthcare law and ethics, therefore. But what exactly do we mean by 'vulnerability' when we refer to it in the context of healthcare law and ethics (HCLE), and what should we mean by it? Must the theory and practice of HCLE adopt an understanding of vulnerability that applies in other contexts too, or should we be seeking a bespoke concept of vulnerability particular to the HCLE setting?

The idea of vulnerability has had a chequered history in HCLE literature. It has figured mainly at the margins of the discourse, where it has tended to be associated with risk, harm, and exploitation, and seen as something undesirable to be minimised or eliminated. Since the turn of the millennium, however, there has been a pronounced shift toward more direct, explicit engagement with the idea of vulnerability.

In this chapter, I will begin by using a Wittgensteinian approach to enquire into what 'vulnerability' currently means in the context of healthcare law and ethics (HCLE). ${ }^{2}$ I will

\footnotetext{
${ }^{1}$ School of Law, University of Strathclyde. I am grateful to the participants at the roundtable event Vulnerability is Good: The Implications for Law of Positive Accounts of Vulnerability, held at Exeter College, Oxford, on 5 July 2017, and to the editors for their very helpful feedback on an earlier draft of this chapter. 2 I will use the terms 'bioethics' and 'healthcare law and ethics' ('HCLE') interchangeably when discussing the discourse that embraces both law and ethics, but when referring to the law only, I will use 'medical law'.
} 
observe that the meaning of vulnerability in healthcare law and ethics is in flux and suggest that, although our thinking, talking, and writing about healthcare seems to be progressing toward a more appropriate engagement with the idea of vulnerability, now would be an appropriate moment to take stock of developments. In the latter part of the chapter I will offer some clarifications, draw some key distinctions, and emphasise some important themes, in order to facilitate the development of our understanding.

\section{Setting the scene: language-games and 'meaning is use'}

It is necessary to begin by enquiring into what vulnerability currently means in HCLE, before we can reflect critically on this and consider whether we want it to retain this meaning, or to mean something else. In relation to enquiries about (current) meaning, Ludwig Wittgenstein famously declared: 'For a large class of cases of the employment of the word "meaning" though not for all-this word can be explained in this way: the meaning of a word is its use in the language. ${ }^{3}$ In other words, if we want to know what we currently understand a word to mean, we must start by gathering examples of the ways in which we use it (as opposed to attempting to construct a definition in the abstract). This is one Wittgenstein's most wellknown and discussed philosophical claims, and it is often summarised in the slogan 'meaning is use'. In order to put this insight into practice, however, we must combine it with another of Wittgenstein's most influential ideas, the notion of the 'language-game'. ${ }^{4}$ This is because the context in which we ought to be looking for examples of use is the particular 'language-game' in which we are searching for meaning.

If words have meaning in the context of particular 'language-games', we need to be able to recognise language-games (and identify the relevant one) in order to discover meaning

\footnotetext{
${ }^{3}$ L Wittgenstein, Philosophical Investigations, trans. GEM Anscombe, PMS Hacker, and J Schulte (Revised $4^{\text {th }}$ edition by PMS Hacker and J Schulte, Blackwell Publishing Ltd, 2009) paragraph 43.

${ }^{4}$ Ibid, paragraph 23.
} 
by observing use. As we might expect, given Wittgenstein's approach to meaning, he never attempts to provide an abstract definition of the term 'language-game' itself, but instead offers examples, dotted throughout the Philosophical Investigations, of situations in which languagegames are being played. Wittgenstein's examples are small-scale: small acts of describing, telling, lying, explaining, instructing and so on count as 'language-games', presumably because Wittgenstein's aim is to show us how language-games are in operation in even the most mundane exchanges. In previous work, I have argued for extending the label 'languagegame' to much larger and more complex linguistic enterprises like fields of academic inquiry (specifically, legal inquiry). ${ }^{5}$ As I have noted, it seems reasonable to interpret Wittgenstein as meaning that '[a]ny instance of language-use in which the participants are sharing a purpose or are 'playing' by shared rules will probably count as a language-game. Language-games will inevitably overlap, and words may have different meanings within different languagegames.' 6

The final point here is of critical importance: since all terms except narrow 'terms of art' are used in a plurality of language-games, and since words derive their meanings from their use in particular language-games, it follows that the same word may turn out to have different (perhaps very subtly different) meanings within these different contexts. An example which springs immediately to mind is 'dignity', which is often observed to have a number of different possible meanings, including 'the intrinsic worth of human beings' (which seems to be its primary use in human rights discourse) and 'noble bearing' (arguably its primary use in lay discourse). Accordingly, we need to know which language-game is the relevant one before we can gather relevant examples for the purposes of inquiring into the term's meaning (how it is used in the context in question).

\footnotetext{
${ }^{5} \mathrm{M}$ Neal (2012), 'Dignity, Law and Language-Games' International Journal of the Semiotics of Law, 25:107-122, $110-111$.

${ }^{6} \mathrm{lbid}, 110$.
} 
Sometimes, controversy about the meaning of a word will arise - or seem to arise within a particular language-game. 'Dignity' is again illustrative here: even within the context of human rights discourse, different writers use 'dignity' to signify different things, and the question arises as to whether one of these uses is correct, and the others mistaken. It might be argued that this is because human rights discourse is not a single language-game at all, but the nexus at which numerous other political, legal, and philosophical language-games intersect; if so, that would explain the difficulty with persuading all participants to converge on one meaning of a word like 'dignity'. If human rights discourse is a single language-game, however - or has become a distinct language-game over time - then I would argue, following Wittgenstein, that it is necessary to agree upon one way of using dignity - one meaning of 'dignity' - that all players of the game abide by. This is, obviously, no mean task, given the centrality the notion of dignity is assumed to have in human rights discourse and the enormous literature devoted to disagreeing about its 'meaning' in that context; but it is a task that we cannot abandon if human rights discourse is to be conducted other than at cross purposes.

Just as different putative meanings may jostle for primacy within the space of a single language-game, conversely the meaning of a word or phrase (like 'vulnerability', for example) may be shared across different language-games because they share roots, purposes, or other relevant features. As I have observed in the context of an argument about the meaning of 'dignity':

Of course the various language-games within law will share a proportion of their terminology, rules, and so forth, in common - some of the terms and concepts used may even mean the same things across different language-games, given the fact that some of the language-games within law may actually be offshoots from a common trunk. In many cases, then, the language-games of law will be very closely related and have some of their purposes, rules and concepts in common, but this will be true to 
varying degrees, and in some cases what seems like a concept occurring in two language-games may instead be two separate concepts sharing the same terminology.7

Thus, a word like 'vulnerability' might turn out to mean the same thing across different language-games, or it might not. One thing to bear in mind, however, is that if, following Wittgenstein, 'meaning is use' (rather than words having fixed meanings that are external to our dealings with them), then we are not 'stuck' with whatever the historical or current meaning of 'vulnerability' turns out to be, since we can agree to use it in a different way in future. This does not mean that we can use it in any way we like, of course, and the condition of widespread agreement would presumably preclude all but a narrow range of potentiallyreasonable uses.

\section{Vulnerability as a marginal idea in healthcare law and ethics}

What has 'vulnerability' traditionally signified, then, in healthcare law and ethics? In light of my Wittgensteinian approach to meaning, this can be translated as asking: how has the term been used, and how is it presently used, in the context of the HCLE language-game? Given that the landscape of healthcare is largely populated by subjects whose physical and mental health is threatened or compromised, and those caring for them, it would be natural to assume that a widespread recognition of the ubiquity of human vulnerability must always have been central in the HCLE literature. This is far from the case, however. Although 'reference to vulnerability is used widely in bioethics',8 nevertheless as Florencia Luna and Sheryl Vanderpoel note,

In the categorical (or traditional) approach to vulnerability in medical and research ethics, those considered 'vulnerable' seem to be drawn up from a list of 'usual suspects': persons with mental or behavioral disorders, prisoners, residents of nursing homes, people receiving benefits or social assistance ,the unemployed, patients in

\footnotetext{
${ }^{7}$ Neal, n5, 110.

${ }^{8}$ A Wrigley (2015), 'An Eliminativist Approach to Vulnerability' Bioethics 29(7): 478-487, 478.
} 
emergency rooms, some ethnic and racial minority groups, homeless persons, nomads, refugees. ${ }^{9}$

Vulnerability, these authors argue, has been regarded as a marginal phenomenon in HCLE, something that affects 'a list of identifiable subpopulations'10 rather than human beings generally. The Belmont Report (1979), commissioned by the US government in the wake of high-profile ethical failures by medical researchers, is one early, and notable, example of this tendency to regard only certain individuals or subpopulations as 'vulnerable'. ${ }^{11}$ So what might explain the tendency to marginalise vulnerability in HCLE?

(i) The liberal, autonomous subject of HCLE

Commentators have often observed that the human subject, as conceived by law in general, is a 'liberal subject', assumed to be rational, autonomous, and independent. As Jonathan Herring has put it recently in the context of a comprehensive discussion of vulnerability in law:

The law is built around the ideal of legal personhood: a man who is autonomous, selfsufficient, in control, capacitous, and independent. For such a man the law gives the legal tools he needs to maintain his status: the rights of autonomy, privacy, liberty, and freedom from state interference. For him, legal rights are designed to keep him free from intrusion. Rights are designed to keep people apart, to give people their space. ${ }^{12}$

Herring warns that the assumption about selfhood that underpins law - 'the assumption that we are competent, detached, independent people who are entitled to have our rights of selfdetermination and autonomy fiercely protected'13 - is false; in fact, it is 'all a dangerous

\footnotetext{
${ }^{9} \mathrm{~F}$ Luna and S Vanderpoel (2013), 'Not the Usual Suspects: Addressing Layers of Vulnerability', Bioethics, 27(6): 325-332, 325.

10 Ibid.

${ }^{11}$ United States (1978), The Belmont report: Ethical principles and guidelines for the protection of human subjects of research (Bethesda, Md.: The Commission)

${ }^{12} \mathrm{~J}$ Herring, Vulnerable Adults and the Law (Oxford: OUP, 2016), 1.

${ }^{13}$ Ibid, 14.
} 
fiction'. ${ }^{14}$ This should lead us to wonder: if it is a dangerous fiction in law generally, how much more fictitious (and dangerous) is the image of the liberal self in the context of HCLE? Yet in HCLE, too, liberal assumptions about selfhood have exerted powerful gravitational force.

Relatively early in the late-twentieth-century flourishing of HCLE as a discipline, one ethical approach quickly gained prominence in the United States, coming to dominate teaching and theorizing about medical ethics there during the decades that followed. 'Principlism', or the 'four principles approach', describes four key ethical principles - respect for autonomy, beneficence (acting in the patient's best interests), non-maleficence ('do no harm'), and justice (fairness and equality) - and understands ethical decision-making in healthcare as being a matter of balancing whichever of the principles are applicable to a given decision (which may be a decision about an individual patient's treatment, or a governance decision, for example about how health resources should be distributed). ${ }^{15}$ Although it has been criticised from a variety of rival perspectives, ${ }^{16}$ principlism has, nevertheless, had an enduring appeal in medical ethics, probably because it offers a user-friendly framework for making complex decisions which, for some, seems to chime with widespread intuitions about morality.

Although the architects of principlism do not explicitly 'rank' the four principles, the principle of respect for autonomy has assumed particular prominence, both within the framework of principlism (one notable proponent of the approach has called it the 'first among equals' ${ }^{\prime 17}$ ), and - importantly - apart from it. The latter point is important because, as

\footnotetext{
14 Ibid, 1

${ }^{15}$ TL Beauchamp and JF Childress, Principles of Biomedical Ethics ( $7^{\text {th }}$ edition) (New York: OUP, 2013).

${ }^{16}$ See S Holm (1995), 'Not just autonomy - The principles of American biomedical ethics', Journal of Medical Ethics, 21(6):332-338; see also the various contributions to a 2003 Festschrift edition of the Journal of Medical Ethics in honour of Raanan Gillon (volume 29(5)).

${ }^{17}$ R Gillon (2003), 'Ethics need principles - four can encompass the rest - and respect for autonomy should be "first among equals"', Journal of Medical Ethics, 29(5):307-312.
} 
Chadwick and Wilson have recently noted, 'prominent UK bioethicists largely rejected the principles-based approach endorsed by the majority of their counterparts in the USA ${ }^{\prime}, 18$ and bioethics in the UK was 'generally regarded less as a stable discipline and more as what Onora O’Neill calls "a meeting ground for a different number of disciplines, discourses and organisations'" ${ }^{19}$ (A small but vocal utilitarian cohort is perhaps the main exception to the general distrust of 'systematic' ethics in the UK.) Nevertheless, the ideal of the autonomous patient and disapproval of the paternalistic professional may be as powerful in the UK as the US, albeit that here, autonomy seems to exist more as a standalone ethical principle in the classical liberal mould, and as a challenge to utilitarianism. Writing about the US context, Carl Schneider remarked in 1998 that 'the law and ethics of medicine are today dominated by one paradigm - the autonomy of the patient', ${ }^{20}$ and few would claim that things have changed substantially since then, on either side of the Atlantic.

Perhaps because it appears to align neatly with the rational, autonomous image of the subject enshrined in liberal law (described by Herring, above), the principle of respect for autonomy has also been influential in the courts' development of medical law, especially in relation to issues like consent and the right to refuse treatment. The absolute right of a competent patient to refuse treatment for any reason or for none, ${ }^{21}$ even when that will result in death, is probably the most potent symbol of the idea's dominance in medical law.

At first glance, all of this emphasis on autonomy and self-determination in healthcare might seem surprising: patients are often (but not always) more than usually dependent, and more than usually susceptible to being hurt and harmed, so that it might seem more natural

\footnotetext{
${ }^{18}$ R Chadwick and D Wilson (2018), 'The Emergence and Development of Bioethics in the UK', Medical Law Review 26(2):183-201, 195

${ }^{19}$ Chadwick and Wilson n18, 187, citing O O'Neill, Autonomy and Trust in Bioethics (Cambridge: Cambridge University Press, 2002), 1.

${ }^{20}$ CE Schneider, The Practice of Autonomy: patients, doctors and medical decisions (New York: Oxford University Press, 1998), 3.

${ }^{21}$ Articulated by Lord Donaldson in the case of Re T[1992] EWCA Civ 18 and reaffirmed in various subsequent cases including St George's Healthcare NHS Trust v S [1999] Fam 26.
} 
to regard them as vulnerable than as independent 'liberal subjects'. Would not a model of subjecthood in which vulnerability is foregrounded be more apt in HCLE? One need not be a particular critic of the liberal model of subjecthood in general to question its application to the subject in this context, surely?

The emphasis on the autonomy of the patient and her ability to decide for herself must be understood in the context of the fact that modern HCLE emerged in the late twentieth century in significant part as a corrective to the 'doctor knows best' paternalism of previous eras. In America, bioethics seems to have emerged as both an academic discipline and a social movement after the 1950s, having as its key figures writers like Paul Ramsey, who questioned the prerogative power of the clinician and the expectation that patients and the public would be passive in the face of it. ${ }^{22}$ In the UK, where the equivalent movement happened decades later (beginning in the 1980s) the most influential actors included the legal academic Ian Kennedy, (who had been very influenced by American bioethics during his time in the United States, and who became a vocal - yet constructive - academic critic of medical paternalism in the UK), and the campaigning Patients' Association, which challenged the profession's 'ownership' of medicine by debating issues of medical ethics in the public square. The antipaternalists who drove the development of HCLE were well aware of professional power, but chose to counter it by minimising talk of vulnerability, instead emphasising 'patient power' and the model of the patient as a rational, autonomous rights-holder, entitled to participate in decision-making and, ultimately, to choose for himself. Accordingly, the image of the patient as autonomous and self-determining might be understood more as a rhetorical/political strategy than as an attempt to reflect the realities of the healthcare encounter.

(ii) Vulnerability as a marginal/background phenomenon

22 P Ramsey, The Patient as Person: Explorations in Medical Ethics (New Haven: Yale University Press, 1970). 
Vulnerability has figured in this autonomy-heavy picture as a background theme. Although not explicit in the 'four principles' approach, nevertheless the idea of vulnerability can be said to be omnipresent in healthcare ethics in a foundational sense, since vulnerability is presupposed by all ethics. As Martha Nussbaum has observed, 'moral excellence is about taking risks to protect human vulnerability: if vulnerability is denied, then the traditional virtues lose their point. ${ }^{23}$ Writing specifically in the context of healthcare ethics, Margrit Shildrick has claimed that 'it is vulnerability itself, of the one and of the other, and the responsibility that it engenders in the one and for the other, that is the provocation of ethical subjectivity'24 and Jacob Dahl Rendtorff considers that 'respect for the vulnerability of the other is the foundation of ethics in our time.'25

As noted earlier in this section, however, explicit concern with vulnerability has tended to be confined to cases involving those identified as 'vulnerable subjects' and 'vulnerable groups'. And this approach is mirrored in law: as Herring explains, in healthcare law and in law generally the concept of capacity - which Herring defines as the ability to make legally-binding decisions for oneself ${ }^{26}$ - operates to draw convenient lines that confine the label 'vulnerable' to narrow subsets of population. 'Capacity', he writes, 'is used by the law as a key marker between the vulnerable and the non-vulnerable.'27 Because of liberal law's commitment to freedom, its starting point is to assume

that adults have capacity, are autonomous, and are able to make decisions for their life which are worthy of respect. The general law's rules apply to such people. There are then special areas of the law which are marked off for those lacking capacity. ${ }^{28}$

\footnotetext{
${ }^{23}$ M Nussbaum (1998), 'Political animals: Luck, love, and dignity' Metaphilosophy 29(4): 273-287, 275.

${ }^{24}$ M Shildrick, Embodying the monster: Encounters with the vulnerable self (London: SAGE, 2002), 102.

25 JD Rendtorff (2002), 'Basic ethical principles in European bioethics and biolaw: Autonomy, dignity, integrity and vulnerability - Towards a foundation of bioethics and biolaw' Medicine, Health Care and Philosophy 5: 235-244, 237.

${ }^{26}$ Herring, n12, 45.

27 Ibid., 45.

28 Ibid., 41.
} 
Thus, in healthcare law as in other areas of law, 'vulnerability' is understood as a characteristic of those whose formal legal capacity is absent, or less than fully-present, such as children and people with mental illnesses or disabilities. Everyone else is dealt with under the default paradigm of independent, autonomous subjecthood. When Herring tells us that those who lack capacity are seen as vulnerable and need protection from themselves and from others',29 the obvious implication is that the majority who are assumed to be capable are seen as 'notvulnerable' and as able to protect their own interests. According to Herring, then, vulnerability is confined, in healthcare law, at least, to specialist areas, its zone of relevance apparently coterminous with the zone of impaired capacity. Although there has historically been a willingness to discuss vulnerability in relation to research subjects, therefore, in the context of ordinary healthcare practice vulnerability seems to have been regarded as a marginal phenomenon.

This is not to say that there were no accounts of medical ethics in the formative decades of HCLE which sought to foreground vulnerability in everyday medical practice. Notably, for example, Edmund Pellegrino and David Thomasma discussed how 'the fact of illness creates vulnerabilities in people that a concerned professional is sworn to address, ${ }^{\prime 30}$ and insisted it was an axiom of medical ethics that 'care must be taken for the vulnerable individual' ${ }^{31}$ As Henk Ten Have has observed, however, in Pellegrino and Thomasma's ethics, vulnerability although applied more widely - is still understood in the context of '[illness] threatening the essential unity of the person...wounding and harming the person' ${ }^{32}$ In other words, it is still a negative view in which vulnerability is something harmful and undesirable. Roberto

\footnotetext{
29 Ibid., 45.

${ }^{30}$ D Thomasma (1990), 'Establishing the Moral Basis of Medicine: Edmund D Pellegrino's Philosophy of Medicine' The Journal of Medicine and Philosophy 15: 245-267, 250.

31 Ibid, 249.

32 H Ten Have (2012), 'Respect for Human Vulnerability: The Emergence of a New Principle in Bioethics' Bioethical Inquiry (2015) 12:395-408, 400.
} 
Andorno has complained that 'modern medical science gives sometimes the impression of being obsessively focused in reducing human vulnerability' as if it was 'an absolute evil to be eradicated.'33

It is also worth making explicit here that when vulnerability is discussed, it is much more frequently associated with the recipients of healthcare - i.e. with patients (and their families), and with 'vulnerable groups' or 'vulnerable populations' who may be more 'at risk' of harm than others - than with healthcare providers. Again, understanding HCLE as (at least historically) an anti-paternalist project renders this entirely predictable: by definition, an antipaternalistic approach regards doctors as relatively powerful and patients as relatively powerless, so that it is the vulnerability of the patient that primarily concerns anti-paternalists.

There are some signs, however, that this tendency to regard vulnerability as applying only to patients/populations is changing. For decades now, literature produced by clinicians themselves, notably by scholars of nursing such as Joyce Travelbee ${ }^{34}$ and Mary Ellen Lashley, ${ }^{35}$ and physician-scholars such as Eric Cassell, ${ }^{36}$ has offered us powerful images of the professional as humanised, vulnerable carer. More recently, a substantial academic literature has described and theorized phenomena like 'moral distress' and 'burnout' in relation to health professionals (sometimes, but not always, in relation to debates about conscientious objection in healthcare);37 and against the background of pressure's on the UK's National

\footnotetext{
${ }^{33} \mathrm{R}$ Andorno, 'Is vulnerability the foundation of human rights?' in: A Masferrer and E García Sánchez (eds.), Human Dignity of the Vulnerable in the Age of Rights (Dordrecht: Springer, 2016), pp 257-272, 265.

${ }^{34}$ See, e.g., J Travelbee, Interpersonal Aspects of Nursing (Second edition) (FA Davis Company, 1971).

${ }^{35}$ See, e.g., ME Lashley, 'Vulnerability: the Call to Woundedness' in ME Lashley, MT Neal, ET Slunt, LM Bergman and FH Hultgren (eds) Being Called to Care (Albany: State University of New York Press, 1994). ${ }^{36}$ See, e.g., E Cassell, The Nature of Suffering and the Goals of Medicine (Second edition) (New York: OUP, 2004).

${ }^{37}$ See, e.g., G Morley, J Ives, C Bradbury-Jones, \& F Irvine (2017), 'What is "moral distress"? A narrative synthesis of the literature' Nursing Ethics https://doi.org/10.1177/0969733017724354; A-L Glasberg, S Eriksson and A Norberg (2007), 'Burnout and "stress of conscience" among healthcare personnel' Journal of Advanced Nursing 57:392; A-L Glasberg, S Eriksson and A Norberg (2008), "Factors associated with "stress of conscience" in healthcare' Scandinavian Journal of Caring Sciences 22:249; G Gustafsson, S Eriksson, G Stranberg and A Norberg (2010), 'Burnout and perceptions of conscience among health care personnel: A pilot study' Nursing Ethics 17:23.
} 
Health Service, contributors to the British Medical Journal have engaged in discussion about the vulnerability of doctors. ${ }^{38}$

Overwhelmingly, however, and almost unbelievably given the realities of the healthcare environment, vulnerability in HCLE has been seen as a marginal phenomenon, thought to be attention-worthy only in particular kinds of case. And a marginal view of vulnerability goes hand in hand with a negative view of it: when we confine vulnerability to the margins, we thereby associate it with the circumstances in which harm, risk, exploitation, and helplessness are most pronounced. As Angela Martin and colleagues noted as recently as 2014, in the healthcare context,

those are considered as vulnerable who are more likely to be exploited, are unable to protect or safeguard their own interests, lack basic rights, are susceptible to additional harm, or are at risk of unequal opportunity to achieve maximum possible health and quality of life. ${ }^{39}$

In the next section, however, I will argue that HCLE is in the process of developing other ways of discussing vulnerability, and that its usage - and therefore its meaning - is currently in flux.

\section{Vulnerability: meaning in flux}

(i) Post-millennial reconsideration of the role of vulnerability

As noted in the previous section, 'vulnerability' has historically been used in HCLE discourse primarily in relation to particular groups and individuals that are regarded as being particularly 'at risk', susceptible to harm, and/or less able to defend their own interests because of impaired capacity. This entails a negative view of vulnerability, and leads to a focus on attempting to reduce or eliminate it. Even some theories in which vulnerability is

\footnotetext{
${ }^{38}$ See, e.g., C Dyer (2013), ‘GMC and vulnerable doctors: too blunt an instrument?’ BMJ 347: f6230; J Munro (2014), 'What I know I owe to patients' BMJ 349: g6734; and M Limb (2016), 'Doctors are emotionally “damaged" by complaints, analysis finds' BMJ 2016 354: i3732.

${ }^{39}$ AK Martin, N Tavaglione, and S Hurst (2014), 'Resolving the Conflict: Clarifying "Vulnerability" in Health Care Ethics' Kennedy Institute of Ethics Journal 24(1): 51-72, 52 (references removed).
} 
acknowledged to be relevant in a wider sense, such as that of Pellegrino and Thomasma, still regard vulnerability as a property of 'patients rather than persons in general...located in the state of being ill, not in the human condition as such', ${ }^{40}$ and seek to minimise it. Thus, vulnerability has traditionally been understood in HCLE through the lens of the 'ideal' of the autonomous, self-determining patient, and seen as an obstacle to that ideal.

Since the turn of the millennium, however, there have been signs that this is changing, and that the alternative, positive accounts of vulnerability that have been developed by feminist writers are beginning to be embraced by mainstream HCLE discourse in a way that disturbs certain key assumptions about vulnerability (in particular, that it is a feature of only some and not all people, and that it is something undesirable that we should seek to reduce or eliminate).

In 1998, as the culmination of a three year project, a group of experts in bioethics and biolaw from twenty-two European Union countries ('the EU group') published the Barcelona Declaration, ${ }^{41}$ a document containing an agreed set of ethical principles and policy proposals which were subsequently expounded in the group's Report to the European Commission titled Basic Ethical Principles in European Bioethics and Biolaw. Autonomy, Dignity, Integrity and Vulnerability (2000). As the title suggest, the Declaration and the Report recognized four 'basic ethical principles' in healthcare ethics: autonomy, dignity, integrity, and vulnerability. In the intervening period, these have come to be known as the 'revised four principles' and contrasted with the classic principlist approach of Tom Beauchamp and James Childress (sometimes called 'Georgetown principlism' because its originators were, at the time they developed it, based at the Kennedy Institute of Ethics at Georgetown University in the USA).

\footnotetext{
40 Ten Have, n32, 400.

${ }^{41}$ The Barcelona Declaration on Policy Proposals to the European Commission on Basic Ethical Principles in Bioethics and Biolaw (adopted in November 1998 by Partners in the BIOMED II Project), available at <hrlibrary.umn.edu/instree/barcelona.html> (accessed 16/01/2019).
} 
Most noteworthy for present purposes is that 'vulnerability' appears as a principle in its own right in the revised list, given equal billing with autonomy (the only principle common to both lists), in stark contrast with its backstage role in classic principlism, presupposed by beneficence and non-maleficience but never to the fore. Jacob Dahl Rendtorff, one of the signatories of the Barcelona Declaration and the ethicist who, with Peter Kemp, is most closely associated with the 'revised four principles' approach, has noted that, although there was 'considerable disagreement' between members of the group about many matters, 'in particular the notion of dignity', nevertheless there was 'total agreement on the importance of articulating the notion of vulnerability' in the document. ${ }^{42}$

The prominence given to vulnerability by the EU group is a radical departure in itself, but the way 'vulnerability' is articulated within the revised four principles approach also raises a number of questions. This articulation by Kemp and Rendtorff in 2008 is representative:

[vulnerability] expresses the condition of all life as able to be hurt, wounded and killed...[and] must be considered as a universal expression of the human condition. The idea of the protection of vulnerability can therefore create a bridge between moral strangers in a pluralistic society, and respect for vulnerability should be essential to policy making in the modern welfare state. Respect for vulnerability is not a demand for perfect and immortal life, but recognition of the finitude of life and in particular the earthly suffering presence of human beings. ${ }^{43}$

Here, vulnerability is clearly understood both as 'universal' (applying to all human beings) and as normative (capable of 'creat[ing] a bridge between moral strangers'); note that Kemp refers not merely to 'vulnerability' but to 'protection of vulnerability' and 'respect for vulnerability'. The idea that vulnerability is something to be 'protected' and 'respected' also indicates a less negative view of vulnerability than is traditionally found in bioethics, and

\footnotetext{
${ }^{42}$ Rendtorff, n25, 242.

${ }^{43}$ P Kemp and JD Rendtorff (2008), 'The Barcelona Declaration' Synthesis Philosophica 46(2): 239-251, 240.
} 
seems to suggest a departure from the 'vulnerability-reducing agenda' and a willingness to embrace vulnerability in some sense.

There is a great deal to unpack here, and in the wake of the EU project, and the academic outputs in which Rendtorff and Kemp advocated their approach, numerous writers have been provoked to reflect afresh on the role and meaning of the idea of vulnerability in the healthcare context. In the first section of this chapter, I claimed that one of the main advantages of a Wittgensteinian approach to meaning, which regards 'meaning as use', is that we are never stuck with whatever the current meaning of a term happens to be; we can alter the meaning of a term like 'vulnerability' by using it differently in future. Since meaning is not an objective 'given', we have some element of choice regarding what words will mean. In fact, in the case of vulnerability, we are faced with several decisions about use/meaning.

In the remainder of this chapter I will seek to explore whether we should understand vulnerability as 'universal' or 'particular' /' situational', or whether we can understand it as both; whether we should understand vulnerability simply as a fact about the human condition, or as also having some degree of normative force; and how we should understand the relationship between vulnerability and autonomy - does focusing on vulnerability necessarily involve a de-prioritising of autonomy, or a different understanding of it? As will become clear, these questions are interlinked.

\section{(ii) Universal or particular?}

I noted earlier that the 'predominant'44 use of the term 'vulnerability' in HCLE has been its use to refer to the heightened susceptibility to harm that individuals or groups experience in conditions of particular risk or helplessness, so that those who are 'vulnerable' are 'those who should be afforded special protection and additional attention in medical research and health

\footnotetext{
${ }^{44}$ Martin et al, n39, 52.
} 
care' ${ }^{45}$ This has had the effects of (i) marginalising the idea of vulnerability in healthcare by treating it as something that arises in 'special cases', and (ii) embedding a view of vulnerability as undesirable, a threat to individual autonomy, and thus something that should be reduced or eliminated where possible.

In the postmillennial literature, however, the hitherto 'predominant' use - signified by terms such as 'particular vulnerability', 'specific vulnerability', 'situational vulnerability', 'variable/selective vulnerability', and/or 'susceptibility' - has been criticised on a number of grounds. Kate Brown, for example, notes the potential for particular vulnerability to be deployed in ways that are 'oppressive, controlling, and exclusive', 46 and summarises academic criticism of it as

[centring] predominantly around three objections: (i) that it is a paternalistic and oppressive idea, (ii) that it functions as a mechanism of widening social control and (iii) that calling individuals or groups 'vulnerable' can act to exclude and stigmatise them, particularly where people's behaviour may not conform to accepted notions of victimhood or innocence. Some authors also note that vulnerability is not necessarily a label that those being singled out as such would identify with. ${ }^{47}$

A concern for many writers is 'the deficit-oriented nature of the term [vulnerability] and its link with stigma'.48 Levine and colleagues caution that the concept of vulnerability stereotypes whole categories of individuals without distinguishing between individuals in the group.' 49

Martin and colleagues point out the potential for 'oversight of some individuals who are inappropriately not regarded as vulnerable.'50 Conversely, other commentators worry that the lack of a settled definition of 'vulnerable' allows for 'almost everyone [to] be classified as

\footnotetext{
${ }^{45} \mathrm{Ibid}$ (emphases added).

${ }^{46}$ K Brown (2011), “"Vulnerability”: Handle with Care' Ethics and Social Welfare 5(3): 313-321, 315.

47 Ibid, 315-316.

48 Ibid, 319.

${ }^{49}$ C Levine, R Faden, C Grady, D Hammerschmidt, L Eckenwiler and J Sugarman (2004), 'The Limitations of "Vulnerability" as a Protection for Human Research Participants' The American Journal of Bioethics 4(3): 44-49, 47.

${ }^{50}$ Martin et al, n39, 52 (emphasis added).
} 
vulnerable in some way', ${ }^{51}$ so that the idea of vulnerability is becoming 'useless as a means of picking out special status' ${ }^{52}$ In the healthcare context specifically, it has been observed that ‘[s]ince its first mention in the Belmont Report (1979), an ever wider range of categories and sub-categories of vulnerable persons has been identified, resulting in seemingly exhaustive lists of vulnerable populations. ${ }^{\prime 53}$ On a slightly different note, I have previously wondered whether a 'vulnerable groups' approach, combined with a 'vulnerability-reducing agenda', might

provide incentives for individuals to perceive and represent themselves as vulnerable in order to qualify for and benefit from enhanced protections or allowances, which in turn could result in a 'competitive vulnerability' wherein different groups and their advocates strive to secure the best 'deals' ${ }^{54}$

These criticisms all focus on the potential harms that might be caused by a 'particular' approach to vulnerability, but such an approach might also be criticised on conceptual grounds, on the basis that it fails to acknowledge - and may even mask - the reality of the human condition. The reality, according to an increasing number of contemporary writers, is that vulnerability is a 'fundamental human constant', 55 an 'essential attribute of mankind'56 and 'an intrinsic element of human life' ${ }^{57}$ Michael Kottow has observed that, in the most recent literature on vulnerability in healthcare, 'two distinct forms of vulnerability need to be unravelled,'58 as what Luna calls the 'traditional' (particular) account is increasingly juxtaposed with references to 'universal', 'inherent', or 'essential' vulnerability.

\footnotetext{
${ }^{51}$ Wrigley, n8, 478.

52 lbid.

53 Ten Have, n32, 398.

54 M Neal (2012), “'Not Gods But Animals”: Human Dignity and Vulnerable Subjecthood' Liverpool Law Review 33:177-200, 186.

${ }^{55}$ M Kottow (2004), 'Vulnerability: what kind of principle is it?' Medicine, Health Care and Philosophy 7: 281287, 285.

56 Ibid, 284.

${ }^{57}$ Andorno, n33, 265.

${ }^{58}$ Kottow, n55, 283 (emphasis added).
} 
Ten Have, for whom 'vulnerability is...a fundamental expression of the human condition'59 credits Onora $\mathrm{O}^{\prime} \mathrm{Neill}^{60}$ with having 'introduced' the distinction between 'persistent' (universal) and 'variable' (particular) vulnerability in 1996. Whatever its origins, the distinction is now widely-observed, and many influential writers advocate for a 'universal' understanding of human vulnerability. The Vulnerability Theory of feminist legal theorist Martha Fineman is one of the best-known examples of a comprehensive theory that proceeds upon the insistence that vulnerability is 'universal and constant, inherent in the human condition',61 but there is increasing support for an acknowledgment of 'universal' vulnerability among those who write about HCLE now too. As mentioned already, the 'revised four principles' approach undoubtedly sees vulnerability in that way, and many other writers are happy to embrace the idea of vulnerability as universal. Ten Have, Roberto Andorno, Kottow, and Herring are just a few notable cases in point; likewise, Wendy Rogers, Catriona Mackenzie and Susan Dodds recently acknowledged that 'all human life is conditioned by vulnerability, as a result of our embodied, finite, and socially contingent existence.' 62

The idea that vulnerability is universal has undeniable intuitive appeal: after all, who can deny that all human beings are susceptible to harm, and dependent on others for our survival? But agreement that universal vulnerability is an anthropological fact is one thing; positing vulnerability as a 'basic ethical principle' 63 and something that deserves our 'respect' and 'protection' (as the revised four principles approach does) is another.

\footnotetext{
59 Ten Have, n32, 401.

${ }^{60} \mathrm{O}$ O'Neill, Towards Justice and Virtue (Cambridge: Cambridge University Press, 1996).

${ }^{61}$ MA Fineman (2008), 'The Vulnerable Subject: Anchoring Equality in the Human Condition' Yale Journal of Law \& Feminism 20(1): 1-23, 1.

62 W Rogers, C Mackenzie and S Dodds (2012), 'Why Bioethics Needs a Concept of Vulnerability' International Journal of Feminist Approaches to Bioethics 5(2): 11-38, 12.

${ }^{63}$ Rendtorff, n25, 241.
} 
(iii) Fact or value?

The distinction between fact and value is a prominent theme in discussions of universal vulnerability. Rendtorff and Kemp, key academic proponents of the revised four principles approach, insist that 'in ordinary language [vulnerability] is not only descriptive but at the same time explicitly normative. Thus, in the discussion of vulnerability we cannot maintain a sharp distinction between fact and norm because vulnerability is mostly always already an ethical concept' ${ }^{64}$ For Rendtorff and Kemp, then, as Ebbesen observes, 'the fact that a person is vulnerable entails a demand to respect the vulnerability of that person.' ${ }^{65}$ But this is robustly contradicted by a number of critics. Kottow, for example, warns that ' $[\mathrm{b}] \mathrm{y}$ stating that humans are vulnerable and that this constitutes an ethical principle, a naturalistic fallacy is being committed.' 66 Andorno, too, is adamant that '[o]ur shared vulnerability is a fact, which cannot have per se any normative effect.' ${ }^{67}$

Martin and colleagues agree that vulnerability cannot 'ground any direct obligation' in and of itself, but point out that it 'exists because we have welfare and agency interests which can be frustrated', and 'the moral importance of these interests, rather than vulnerability itself' is capable of generating moral obligations. ${ }^{68}$ Andorno makes the same point when he acknowledges that, although vulnerability per se is purely descriptive and 'deprived of any normative value,'69 nevertheless it has normative implications in combination with the recognition that human beings have intrinsic worth:

legal systems take into account the fact that we are ontologically vulnerable and, for that reason, recognize rights and establish procedures for ensuring their respect. But they have previously assumed that we have inherent dignity. In sum, if the fact that

\footnotetext{
$64 \mathrm{~J}$ Rendtorff and P Kemp, Basic ethical principles in European bioethics and biolaw. Vol. 1 : autonomy, dignity, integrity and vulnerability (Denmark: Centre for ethics and law, 2000), 46.

65 M Ebbesen (2011), 'Two Different Approaches to Principles of Biomedical Ethics: A Philosophical Analysis and Discussion of the Theories of the American Ethicists Tom L Beauchamp and James F Childress and the Danish Philosophers Jakob Rendtorff and Peter Kemp' International Journal of Ethics 7(3/4): 233-245, 241.

${ }^{66}$ Kottow, n55, 28.

${ }^{67}$ Andorno, n33, 265.

${ }^{68}$ Martin et al, n39, 62 (emphasis added).

${ }^{69}$ Andorno, n33, 270.
} 
we are vulnerable leads to the recognition of human rights, it is because we are dealing with the vulnerability of a kind of beings that possess inherent worth. ${ }^{70}$

This insight is important, as it explains how observations about 'universal vulnerability,' while undoubtedly descriptive of an anthropological fact, can - in theory, at least - have normative implications/generate moral obligations when combined with evaluative premises about human worth (I will return to this point later). Some other criticisms of the idea of 'universal vulnerability' as an ethical principle must also be mentioned, however.

One of the most frequent criticisms is that 'vulnerability' is an inescapably vague and meaningless term. As Ten Have acknowledges, 'the notion of vulnerability is criticized as being too vague, too narrow, and too broad. It is often used as a "conversation stopper". There is no commonly accepted definition.' ${ }^{\prime 71}$ Because there is no simple, uncontroversial way of defining vulnerability, he agrees, the idea 'does not provide clear moral guidance.'72

Anthony Wrigley argues that the we should stop attempting to use the term 'vulnerability' in normatively load-bearing ways; he claims that it is not a normativelysubstantive concept and has 'no genuinely explanatory role' since it does not express anything about the world which is not already captured more usefully by other familiar concepts. ${ }^{73} \mathrm{We}$ should use vulnerability 'only as a kind of warning or signal', he says, 'a linguistic marker drawing our attention towards already well-understood ethical concepts and concerns such as physical harms or exploitation.' 74

Very similar sorts of criticism have also been levelled against the idea of 'dignity'. Dignity, too, has been criticised on the basis that it is 'difficult to fathom', 75 that it is too

\footnotetext{
${ }^{70}$ Ibid. Note that Andorno is using 'dignity' and 'intrinsic worth' synonymously here.

71 Ten Have, n32, 397, references removed.

${ }^{72} \mathrm{Ibid}$, references removed.

${ }^{73}$ Wrigley, n8, 478.

74 Ibid, 479.

${ }^{75}$ Advocate-General Christine Stix-Hackl in the case of Omega Spielhallen und Automatenaufstellung GmbH v Oberbürgermeisterin der Bundesstadt Bonn [2004] ECR I-9609, paragraph 74.
} 
subjective and 'hardly up to the heavyweight moral demands assigned to it', ${ }^{76}$ and that it means nothing that is not captured more effectively by other values (like autonomy and respect for persons). ${ }^{77}$ Even some of its supporters have acknowledged that dignity is essentially a 'rhetorical ornament' 78 - something people mention 'when they want to sound serious but are not sure what to say'79 - and that conceptually, it is 'in such disarray that it does not provide even a minimally stable frame for global discourse and action.' ${ }^{80}$ All of this has led me to observe, elsewhere, that 'a number of academic commentators... deny that [dignity] is normatively meaningful or that it can have anything other than a polemical value in ethical debates.' ${ }^{81}$ Yet I was - and still am - unconvinced by these denials, since

A range of vague and contested concepts, such as justice, fairness, reasonableness, mercy and compassion, are arguably indispensable to an understanding of what 'law' is (as distinct from force, power, control, tyranny, and so on)... [A]ny claim that dignity should be ignored or derided simply because it appears vague and contested ought to make us ask whether we may also ignore similarly vague/contested concepts such as justice, fairness, mercy and compassion... In practice, we base a great deal on unscientific, contested concepts all the time. ${ }^{82}$

I tend to agree with Jeremy Waldron, therefore, that

Conceptual definition is a complicated business and the idea that it always involves the precise specification of necessary and sufficient conditions must be regarded as naive and outdated. A term which cannot be given a watertight definition in analytic jurisprudence may nevertheless be useful and important for social and political theory; we must not assume in advance that the imprecision or indeterminacy which frustrates the legal technician is fatal to the concept in every context in which it is deployed. 83

\footnotetext{
${ }^{76}$ S Pinker (2008), 'The stupidity of dignity' The New Republic, available at <www.tnr.com/article/the-stupiditydignity> (accessed 16/01/2019).

${ }^{77} \mathrm{R}$ Macklin (2003), 'Dignity is a useless concept' BMJ 327: 1419-1420.

78 LR Barroso (2012), 'Here, There and Everywhere: Human Dignity in Contemporary Law and in the Transnational Discourse' Boston College International and Comparative Law Review 35(2): 331-93, 333.

79 J Waldron (2012), 'How Law Protects Dignity' Cambridge Law Journal 71(1): 200-222, 201.

80 D Mattson and S Clark (2011), 'Human dignity in concept and practice' Policy Sciences 44: 303-319, 305.

${ }^{81} \mathrm{M}$ Neal (2016), 'Discovering Dignity: Unpacking the Emotional Content of "Killing Narratives"' in H Conway and J Stannard, The Emotional Dynamics of Law and Legal Discourse (Oxford: Hart, 2016), 83.

82 Neal, n5, 117.

$83 \mathrm{~J}$ Waldron, The right to private property (Oxford: Clarendon, 1988), 31.
} 
Ideas can be indeterminate and resist agreed definition, yet still express something indispensable. 'Dignity' seems to be one such concept, and 'vulnerability' (in its universal sense) is arguably another. Indeed, as Ten Have remarks, '[i]t is striking that nearly all scholars, critical or not, concur that the notion of vulnerability should not be abandoned since it is already so common.' 84

However, a couple of the points Wrigley makes can lead us to some important insights about universal vulnerability. First, he says that

The problem with [universal vulnerability] is that if we are all vulnerable and we are vulnerable in virtue of this being a natural fact about us, then trying to avoid it or seeking special protection because of it becomes largely futile as it is simply a natural part of everyone's existence. ${ }^{85}$

This is only a problem with universal vulnerability if we are 'trying to avoid it or seeking special protection because of it'. But those who appeal to universal vulnerability seem not to use the idea in this way, i.e. as a marker of special concern existing in the context of a vulnerability-reducing agenda. That is how particular vulnerability is used, so as noted above, it is fair to criticise accounts of particular vulnerability in which the label 'vulnerable' is attached so indiscriminately as to render almost everyone 'vulnerable', and the status itself essentially meaningless (if everyone is particularly vulnerable, then no-one is). But the criticism is only valid in that context because there is a clear need to restrict the scope of that kind of vulnerability. In the case of universal vulnerability, there is no such need, since the point is not to highlight the particular vulnerability of only some people: quite the contrary. As such, criticisms of over-extension can be legitimate only in the context of particular vulnerability. It is important to be clear about this, and Wrigley's critique helps to bring it out.

\footnotetext{
${ }^{84}$ Ten Have, n32, 397.

85 Wrigley, n8, 482.
} 
Wrigley also makes the following point about what kind of ethical function he thinks universal vulnerability can, and cannot, perform:

[universal vulnerability] is far too broad to act as anything other than an underlying presumption about all human beings and is unable to generate ethical duties that go beyond what we would owe to every human in virtue of their being human. This is problematic...86

But is it problematic? What if the proper role of universal vulnerability is far more foundational, and the work that we need it to do is not to generate any specific ethical rule(s) or principle(s), but rather to describe more accurately the foundations of our ethical selfhood in relationship with one another - to reposition/recalibrate our understanding of ourselves and one another, as a corrective to liberal myths? This may sound like a purely descriptive role, but insofar as our normative conclusions are premised on perceived 'facts' about ourselves, a serious acceptance of universal human vulnerability would have normative implications. This links back to the insight that, although acknowledgment of universal vulnerability is a recognition of anthropological fact, it can be a legitimate basis for moral claims when combined with normative premises (for example, that all human beings possess are intrinsically morally valuable).

Such a 'foundational' function alone may not be enough, however. Wrigley, for example, insists that if 'vulnerability' is to be analytically-useful (and ultimately he concludes that it is not), we also need it to do the work of 'identify[ing] cases where people or groups are open to harm in ways that are different to a standard norm for humans.' ${ }^{87}$ In other words, there is a need for the marking-out function that 'particular' vulnerability can perform, whether or not vulnerability also has a foundational role in our ethics. This seems to be

\footnotetext{
${ }^{86} \mathrm{Ibid}$.

$87 \mathrm{lbid}$.
} 
supported by Rogers and colleagues when they acknowledge that 'vulnerability is universal; at the same time, many vulnerabilities are context-dependent and demand ethical responses because of their significance within a particular setting. ${ }^{\prime 88}$

Perhaps, then, we want to use vulnerability in both of its 'two forms'; perhaps we need to 'unravel' them not in order to choose one usage over the other, but in order to understand and use them both. Is it open to us to choose this? Several commentators see no issue with using vulnerability in both ways simultaneously. Martin and colleagues, for example, regard the difference between the two uses as quantitative rather than qualitative:

the two apparently disparate views of vulnerability are neither competitive nor contradictory. In fact, they depend on each other, since they refer to the very same concept with different likelihoods of manifestation: the notion of vulnerability requiring protection just for some needs to be embedded into the view that vulnerability encompasses everyone. ${ }^{89}$

As such, in their view, 'the controversy concerning the scope of vulnerability does not represent a true problem but rather a philosophical pseudo problem.' ${ }^{90}$ Herring agrees that there is no contradiction in using vulnerability in both the universal and particular senses 'once it is recognized that the second understanding is seeking to identify a category of people who are vulnerable in a way above and beyond the way we are all vulnerable. ${ }^{91}$

As has been mentioned already, however, any proposal for a dual-use approach must contend with the fact that the use of vulnerability to mark out particular at-risk groups or individuals has been challenged, and not only on the basis of over-extension leading to meaninglessness. As touched on above, some critics argue that this usage paints vulnerability as negative/undesirable/ to be minimized, thus stigmatizing those who are said to possess it; and that it can be deployed in paternalistic or controlling ways. But I want to offer a suggestion

\footnotetext{
${ }^{88}$ Rogers et al, n62, 12.

89 Martin et al, n39, 53.

90 Ibid (emphasis added).

${ }^{91}$ Herring, n12, 7.
} 
up for consideration: namely, that while these pitfalls may apply to the 'particular' form of vulnerability when it is the only sense in which 'vulnerability' is used, they may be less likely to materialize if 'particular' and 'universal' senses of vulnerability are both used within an analytical framework. This is admittedly no more than speculation on my part at the moment; but I wonder whether the presence of a foundational acknowledgment that we are all inescapably vulnerable, and that 'particular' vulnerability is simply a heightening of the vulnerability that characterizes all of us all of the time, might work to mitigate any tendency to over-extend particular vulnerability, to adopt an overly-negative view of it, and to stigmatize those said to possess it. If the universal/particular distinction were to be seen as merely a 'matter of degree', these problems may be less pronounced.

Before concluding, it is necessary to return to a subject raised earlier: namely, Andorno's insight that in order for a statement about human vulnerability to have normative force and generate moral obligations, as opposed to being a simple description of anthropological fact, it must be combined with a normative premise about human beings. Note that this point applies to statements about universal and particular vulnerability alike. The vulnerability of humans makes ethical claims on us because we hold pre-existing evaluative beliefs about human beings (for example, that they possess dignity or intrinsic value); so that their vulnerability, when we encounter it, is appreciated as the vulnerability of morally-relevant or morally-important beings, and demands a response from us because we value the beings whose interests are threatened by it. Catriona Mackenzie makes essentially the same point when she writes about the 'entwinement' of our vulnerability and neediness with the 'morally salient' characteristics of human beings such as 'our rational, emotional and agential capacities, as well as our capacities to suffer and to experience well-being', and claims 
that ' $[\mathrm{t}]$ he aim of developing an ethics of vulnerability...is to highlight this entwinement and hence the moral salience of vulnerability.' ${ }^{92}$

An immediate issue here is that the main candidates for the normative premises that might be conjoined with the fact of vulnerability to yield ethical obligations are themselves often criticized as indeterminate, multiply-valent ideas. The examples Andorno cites - dignity and intrinsic worth - are cases in point: concepts endowed with a range of contradictory, controversial meanings. I have already said that I do not regard ideas as useless or purely polemical on this basis; on the contrary, I believe that essentially-contested concepts can and do perform important functions in our ethical and legal discourse. Nevertheless, if our aim is to 'cash out' the idea of vulnerability into practical normative guidance, trying to do so by reference to other contested concepts without defining precisely what we mean by them is unlikely to take us very far. It seems like common sense to look for normative premises that are as clearly-defined as possible.

\section{(iv) Vulnerability and autonomy}

Another concern arises if the normative premises we cite ultimately make the normativity of vulnerability depend on individual autonomy, because this would create the risk that our theorizing about vulnerability, and our application of it, would slip full-circle back into the liberal mythology that the mainstreaming of vulnerability is an attempt to redress. This risk would arise, for example, if we were to take, as our normative premise, a version of human dignity or intrinsic worth that is too closely bound up with individualistic or atomistic notions of autonomy; or an idea like 'personhood' which tends to draw heavily on cognitive capacities and the capacity for self-determination.

\footnotetext{
${ }^{92}$ C Mackenzie, 'Vulnerability, Needs, and Moral Obligation' in C Straehle (ed), Vulnerability, Autonomy and Applied Ethics (New York: Routledge, 2017), 92.
} 
How, then, can we theorize vulnerability in a way that minimises the risk of sliding back into an over-emphasis on individual autonomy? One option is to choose normative premises in which autonomy is not the focus. There are accounts of human dignity, for example, which do not particularly emphasize autonomy. In my own previous writing, I have argued that what we value when we respect 'human dignity' is the apparently-unique sense in which humanity, and human life, embodies a balancing of the fragile/material/finite and the transcendent/sublime/immortal:93

[W] hat is distinctive about dignity and differentiates it from other "grand" principles of ethics, like autonomy, or sanctity, is ..that it gives vulnerability a place of honor...what we value when we invoke 'dignity' is a kind of balancing, or equilibrium, which is only valuable, or admirable, because we are vulnerable...[N]ot only is vulnerability a necessary condition without which this kind of good would not be possible; it is an essential part of the good of dignity. Other ethical principles respond to vulnerability too, but they value entities and actions either in spite of vulnerability, regardless of it, or to the extent that it is overcome. Dignity, on the other hand, treats vulnerability as a source of value. ${ }^{94}$

In claiming this, I am arguing for a unique form of what Mackenzie calls the 'entwinement' of vulnerability with a morally-salient characteristic; namely that vulnerability is a prerequisite for, and a component of, the value of human dignity. Various others have also recognized that autonomy is only part of the dignity picture, and have appreciated the importance of respecting dignity in conditions of reduced or absent autonomy. ${ }^{95}$

Arguably, however, there is a need, when theorizing vulnerability, to 'pay sufficient attention to obligations to foster agency and autonomy ${ }^{\prime 96}$ alongside the obvious focus on meeting needs and protecting against harm, in order to avoid paternalism. ${ }^{97}$ As Rogers and colleagues argue:

\footnotetext{
93 Neal, n54.

94 Ibid, 198 (emphasis in original).

95 See, e.g., B Hale (2009), 'Dignity' Journal of Social Welfare and Family Law 31(2): 101-108.

${ }^{96}$ Rogers et al, n62, 22.

97 Ibid, 23.
} 
If human persons are both vulnerable and capable of autonomy, then we need an account of autonomy that is premised on recognition of human vulnerability, and we need an analysis of vulnerability that explains why we have obligations not only to protect vulnerable persons from harm, but to do so in a way that promotes, whenever possible, their capacities for autonomy. ${ }^{98}$

The key, they say, is to strike the appropriate balance between protection and support for autonomy, and they consider that relational theories of autonomy are best suited to this task, since

[Relational] autonomy is... premised on the fact of our inescapable dependency on, and hence vulnerability to, others. Moreover, because relational theorists regard agency and some degree of autonomy as important for a flourishing human life, a relational approach is committed to the view that the obligations arising from vulnerability extend beyond protection from harm to the provision of the social support necessary to promote the autonomy of persons who are more than ordinarily vulnerable..$^{99}$

What we might seek to avoid, then, may not be normative premises that emphasize autonomy at all, but ones that emphasize the individualistic liberal-legal vision of autonomy that helped to edge the idea of vulnerability out to the margins of HCLE discourse in the first place. Relational accounts of autonomy seem to offer a particularly promising alternative vision, since any foregrounding of relationships necessitates a focus on the sorts of factors - such as openness and interdependence - that are also bound to be central to discussions of vulnerability. ${ }^{100}$ Relational accounts may also be particularly useful in the healthcare context because they tend to emphasize the embodied nature of the subject. 101

\footnotetext{
98 Ibid.

${ }^{99}$ Rogers et al, n62, 24.

${ }^{100}$ For a seminal collection of essays on relational autonomy, see C Mackenzie and N Stoljar, eds., Relational Autonomy: Feminist Perspectives on Autonomy, Agency, and the Social Self (New York: Oxford University Press, 2000). For a very recent assessment of relational autonomy in the clinical context, see ES Dove, SE Kelly, $F$ Lucivero, M Machirori, S Dheensa and B Prainsack, 'Beyond individualism: Is there a place for relational autonomy in clinical practice and research?' (2017) Clinical Ethics 12(3): 150-165.

101 JK Walter and LF Ross (2014), 'Relational autonomy: moving beyond the limits of isolated individualism' Pediatrics 133, Supplement 1: S16-S23.
} 
Another kind of 'alternative' account of autonomy is Onora O'Neill's 'principled autonomy'. ${ }^{102}$ In contrast with many contemporary accounts, O'Neill understands autonomy not as being about 'independence or self-determination or self-expression', 103 but rather, following Kant, as a matter of 'acting on...principles of obligation.'104 This is, she says, 'a different and older view of autonomy' 105 than the individual autonomy emphasized within classic principlism. A key feature of $\mathrm{O}^{\prime}$ Neill's account is its strong emphasis on trustworthiness. Claudia Wiesemann notes that vulnerability is a prerequisite for trust. ${ }^{106}$ She quotes Carolyn McLeod's observation that someone who trusts 'must be able to accept that by trusting, s/he is vulnerable, in particular to betrayal' 107 and reflects that, this notwithstanding, relationships involving vulnerability and trust - she cites the parent-child relationship and romantic partnerships, among other examples - are 'considered very rewarding types of relationship.' ${ }^{108}$ Moreover, this is 'because of the vulnerability involved, not despite it. Since we cherish the idea that someone is committed to promote our personal good we welcome relationships that are characterized by vulnerability and trust.' ${ }^{109}$ Vulnerability cannot be 'bad per se', 110 therefore, because it is a prerequisite for something 'we all value', 111 namely relationships of trust.

When we understand vulnerability through the lens of trust, according to Wiesemann, this also enables us both to appreciate vulnerable people as active moral agents, and to better understand the nature of our moral obligations toward them. First, Wiesemann argues that 'by bestowing and refusing trust', a vulnerable person 'actively engages in relationships with

\footnotetext{
102 O O'Neill, Autonomy and Trust in Bioethics (Cambridge: Cambridge University Press, 2002).

103 Ibid, 62.

104 Ibid, 84.

105 lbid, 73-74.

${ }^{106}$ C Wiesemann, 'On the Interrelationship of Vulnerability and Trust' in C Straehle (ed) Vulnerability, Autonomy and Applied Ethics (New York: Routledge, 2017), 157-170.

${ }^{107}$ C McLeod, cited in Wiesemann, nxxx, xxx.

108 Wiesemann, nXXX, xxx.

109 Ibid, xxx (emphasis added).

110 Ibid, xxx.

111 Ibid, XXX.
} 
those who are to protect her in her vulnerability'112 and so 'should be considered an active moral agent in her relationships.'113 Thus, for Wiesemann, '[c]onceptualizing vulnerability in terms of trust helps to orientate the decision-making process toward the (potentially) vulnerable as moral agents' instead of them being 'patronized and reduced to passive objects of care.'114

Moreover, making the relationship between vulnerability and trust explicit helps clarify that the kind of obligations that are owed to vulnerable people are obligations owed 'to persons who trust.'115 This does not give us precise information about the content of our obligations, since the appropriate moral response to trust will be person- and context- specific. But Wiesemann's key point is that when we encounter vulnerability, the most appropriate moral response will not necessarily be to seek to reduce or eliminate it, even where that is possible. There are two possible responses to vulnerability: one is 'to minimize the need to trust', but the other is 'to invest in those factors assuring and maintaining trustworthiness.' 116 In the healthcare context, specifically, minimizing vulnerability and the need to trust 'is not realizable in every situation given the complexities of medical progress and the natural limitations of (patient) autonomy.'117 Therefore, trusting in the 'integrity and goodwill of a health care practitioner' will often be a reasonable way (and indeed, may be the only possible way) for a patient to respond to her vulnerability and face 'the complexities of medical treatment.'118

Wiesemann concludes that each both types of response to vulnerability can be appropriate in different contexts; sometimes, we should respond to vulnerability by seeking

\footnotetext{
112 Ibid, Xxx.

113 Ibid, $x x x$.

114 Ibid, xxx.

115 Ibid, XXX.

116 Ibid, XXX.

117 Ibid, XXX.

118 Ibid, XXX.
} 
to minimise it, and at other times by trusting, or encouraging trust. ${ }^{119}$ If, as she argues, each is 'indispensable for controlling vulnerability'120 (including in healthcare), this entails that it is necessary to create and sustain a culture wherein trust is encouraged and rewarded. As Wiesemann's work makes explicit, relationships of trust inevitably involve vulnerability, so that accounts which emphasise trustworthiness are accounts in which the subject is necessarily understood as vulnerable (even while her autonomy is being emphasised). In both 'relational' and 'principled' accounts of autonomy, therefore, we find autonomy theorized in ways that acknowledge the subject as simultaneously autonomous and vulnerable. Just as it seems there is no need to choose between the universal and particular understandings of vulnerability, then, neither does there appear to be any need to choose between valuing vulnerability and valuing autonomy.

\section{Conclusion}

When analysing engagement with the idea of vulnerability in HCLE scholarship, it is analytically useful to identify two distinct periods. In the late twentieth-century, the dominant voices in HCLE were those that promoted an ideology of the patient as individually autonomous and self-determining, with a resultant marginalization of vulnerability to 'special cases' in which autonomy was significantly impaired. By contrast, the early postmillennial literature has seen many HCLE scholars - led by feminist theorists both inside and outside healthcare scholarship - seeking to reclaim the idea of vulnerability from the margins, and to place it front and centre in theorizing healthcare. This new willingness to reflect on vulnerability has latterly included a willingness to discuss the vulnerability of healthcare professionals as well as patients.

\footnotetext{
${ }^{119}$ Wiesemann, XXX

${ }^{120}$ Wiesemann, $X X X$
} 
In this chapter, I have used a Wittgensteinian approach to meaning to argue that the use, and therefore the meaning of 'vulnerability' in HCLE is in flux, and that we have a choice about what it will mean in future. My purpose here has not been to advocate for any particular use of the term, but rather (i) to note that we have a choice, and (ii) to offer some observations that I hope may inform the debates to come.

I have argued that we do not necessarily need to choose between the 'particular' and 'universal' senses of 'vulnerability'; we do not need to decide that vulnerability will either continue in its marginal role, or cease to be used in relation to particularly-vulnerable individuals and groups altogether. I have suggested - tentatively - that the particular and universal senses of vulnerability can be used in combination, and that they might even turn out to be complementary.

Observations about human vulnerability (either particular or universal) can only generate normative conclusions, however, in combination with evaluative premises about the importance of human beings' interests (and so ultimately about the importance of human beings themselves). I have cautioned here against appealing to premises that are themselves dependent on indeterminate or contested ideas, since this will decrease the likelihood of reaching agreement about what the term 'vulnerability' ought to signify in HCLE discourse. I have also cautioned against premises that would render the meaning of 'vulnerability' dependent on a liberal-individualistic conception of autonomy, since that image of the subject seems to have contributed to the marginalization of vulnerability in the first place, and I have suggested that 'relational' and 'principled' accounts of autonomy are more naturally compatible with vulnerability.

Ultimately, it is for us - the participants in the HCLE language-game - to determine the future meaning of 'vulnerability' within that context, by agreeing how we will use it. That, in turn, will depend on what work we want the idea to do. 